\title{
Self-evaluation of medical students on the elective research course
}

\author{
Rasidah Abd Wahab ${ }^{1}$, Zunika Amit ${ }^{2}$ \\ ${ }^{1}$ Medical Education Unit, Universiti Malaysia Sarawak, Malaysia, ${ }^{2}$ Department of Basic Medical Sciences, \\ Universiti Malaysia Sarawak, Malaysia
}

\section{ARTICLE INFO}

Received

Accepted

: 21/03/2013

Published

$: 16 / 12 / 2013$

: 09/03/2014

\section{KEYWORD}

Elective research course

Medical student

Self-evaluation

\section{ABSTRACT}

The significance of learning research methodology and performing research has been accepted by various medical schools in Malaysia as well as in other countries. The aim of integrating research into medical curriculum is to inculcate the research culture and form part of the evidence-based practice among medical professionals. Hence, the Faculty of Medicine and Health Sciences, Universiti Malaysia Sarawak has incorporated the research component into the preclinical year of the medical curriculum. A survey was conducted to gauge the second year medical students' level of knowledge of research process at the end of the course using a set of questionnaires. Seventy nine of second year medical students participated in the study. The outcome of the study shows significant improvement in the students' knowledge on research components after completing the one year course $(\mathrm{p}<.05)$. Our findings suggest that the course has met its main objectives to make the students better understand the research processes. It is recommended that further evaluation should be conducted to refine the course.

(C) Medical Education Department, School of Medical Sciences, Universiti Sains Malaysia. All rights reserved.

CORRESPONDING AUTHOR: Rasidah Abd Wahab, Medical Education Unit, Faculty of Medicine \& Health Science, Universiti Malaysia Sarawak, Lot.77, Sect.22, K.T.L.D., Jln Tun Ahmad Zaidi, 93150 Kuching, Sarawak. Email: awrasida@fmhs.unimas.my

\section{Introduction}

The early exposure to undergraduate research is considered essential in a modern undergraduate medical curriculum [1, 3]. The introduction of research component into the undergraduate curriculum has been discussed at length in a variety of disciplines including engineering, medicine, biology, physiology, neuroscience, psychology and so forth. There are numerous benefits for undergraduate students to get involve in conducting research. It allows students to better understand published works, enhance their team-building, explore their research interest and learn how to conduct research [2]. The students' awareness on opportunities to conduct research and making choices of their own research skills are essential to entrench a research culture into undergraduate medical education $[3,7]$.

A few studies have stated the importance of incorporating training in research as part of medical education. Doing research is essential to inculcate critical thinking, reasoning skills and to develop positive attitudes towards scientific research amongst medical students from the beginning of their carrier. The studies also show 
that early involvement in research can promote a tendency to continue doing research in the later stages of medical profession $(1,4-6]$.

There is variation on how research course is implemented or integrated into the medical curriculum. Some medical schools offered the course as an elective or required as part of the syllabus; or conducting one year project or a small project within a month; or incorporate research as part of the didactic activity $[1,7,8]$.

Likewise, in the Universiti Malaysia Sarawak, while other undergraduate programmes require the students to carry out research projects during the final year of their study, the Undergraduate Medical Programme at Faculty of Medicine and Health Sciences, Universiti Malaysia Sarawak make it compulsory to their second year students.

This article is presenting the baseline finding of our elective research course evaluation. The survey was performed to evaluate the students' perception on their level of knowledge of research processes at the beginning and at the end of the course.

\section{Methods}

The second year medical students are required to take the Elective 1 (MDP20505) course as part of the fulfilment for the Degree of Bachelor of Medicine. This course contributes to 5 credits and calculated as 200 hours over a period of one year. The main objectives of Elective 1 course are to give research exposure and provide an opportunity for the Year 2 medical students to participate and appreciate the processes involved in a research. This course will provide basic knowledge and experience besides cultivating their interest in research works. The assessment of this course is quite thorough which includes proposal write-up, poster presentation, oral presentation, project report and the supervisors' report.

A cross sectional survey was done among 104 Year 2 medical students of academic session of 2011-2012 that enrolled for Elective 1
(MDP20505) course. A set of questionnaire was devised to evaluate the students' perception on their level of knowledge of research processes at the beginning and at the end of the course. The questionnaire consisting of 10 items were distributed to students immediately after the end of their elective 1 course. The following items were included in the survey questionnaire:

1. Selection of research topic

2. Writing introduction section for the research proposal

3. Conducting and writing literature review for the research proposal

4. Writing methodology section for the research proposal

5. Creating data file and conducting data analysis

6. Writing finding section for the research report

7. Writing discussion section for the research report

8. Writing conclusion section for the research report

9. Writing references for the research report

10. Overall knowledge on research process

Before the questionnaires were distributed, the students were briefed on the purpose of the survey and the questionnaire itself. The briefing was done to clarify certain terms that were unclear to the students. In the questionnaire, for each of the items, students were asked to rate themselves on the perceived level of knowledge and competency before and after the completion of the course. Students were required to rate themselves according to the following rating scale; 1 very weak; 2 poor; 3 average; 4 good and 5 excellent.

Statistical Package for Social Science version 21 was used to analyse the data. Descriptive analysis was done and Paired T-test was calculated to evaluate the change in score of students' level of knowledge and competency. $\mathrm{P}$ value of $<0.05$ is taken as significant. 


\section{Result}

A total of seventy nine (79) questionnaires were returned giving a response rate of $76 \%$. Table 1 summarized the background of the students participating in this study. Thus, of the respondents, 25 (32\%) were male with a response rate of $75 \%$ and 54 (68\%) were female with a response rate of $78 \%$. Of the 79 respondents, 40 (51\%) students chose to do labbased research and 39 (49\%) conducted non labbased research. An example of a non lab-based research was research that was using questionnaire as a research tool.

Table 1: Characteristic of Elective Students by gender and nature of research $(n=79)$

\begin{tabular}{lc}
\hline Variable & Medical student (\%) \\
\hline Gender & $25(31.6)$ \\
Male & $54(68.4)$ \\
Female & \\
\hline Nature of research & $40(50.6)$ \\
Lab-Based Research & $39(49.4)$ \\
Non Lab-Based Research &
\end{tabular}

Table 2: The changes of students' level of knowledge before and after completing the course (n=79)

\begin{tabular}{|c|c|c|c|c|c|c|}
\hline \multirow{2}{*}{ Item } & & \multicolumn{5}{|c|}{ Student's Self-Evaluation Feedback (\%) } \\
\hline & & Mean & ( \pm SD) & Mean difference (95\% CI) & df & p-value \\
\hline \multirow{2}{*}{ Item 1: Selection of research topic } & Before & 1.09 & 0.29 & \multirow{2}{*}{$-.696(-0.800,-0.592)$} & \multirow{2}{*}{78} & \multirow{2}{*}{$<0.001$} \\
\hline & After & 1.78 & 0.41 & & & \\
\hline \multirow{2}{*}{$\begin{array}{l}\text { Item 2: Writing introduction section for } \\
\text { the research proposal }\end{array}$} & Before & 1.05 & 0.22 & \multirow{2}{*}{$-.658(-0.765,-0.551)$} & \multirow{2}{*}{78} & \multirow{2}{*}{$<0.001$} \\
\hline & After & 1.71 & 0.46 & & & \\
\hline \multirow{2}{*}{$\begin{array}{l}\text { Item 3: Conducting and writing literature } \\
\text { review for the research proposal }\end{array}$} & Before & 1.05 & 0.22 & \multirow{2}{*}{$-.633(-0.741,-0.524)$} & \multirow{2}{*}{78} & \multirow{2}{*}{$<0.001$} \\
\hline & After & 1.68 & 0.47 & & & \\
\hline \multirow{2}{*}{$\begin{array}{l}\text { Item 4: Writing methodology section for } \\
\text { the research proposal }\end{array}$} & Before & 1.10 & 0.30 & \multirow{2}{*}{$-.645(-0.753,-0.538)$} & \multirow{2}{*}{78} & \multirow{2}{*}{$<0.001$} \\
\hline & After & 1.75 & 0.44 & & & \\
\hline \multirow{2}{*}{$\begin{array}{l}\text { Item 5: Creating data file and conducting } \\
\text { data analysis }\end{array}$} & Before & 1.10 & 0.30 & \multirow{2}{*}{$-.683(-0.794,-0.573)$} & \multirow{2}{*}{78} & \multirow{2}{*}{$<0.001$} \\
\hline & After & 1.78 & 0.41 & & & \\
\hline \multirow{2}{*}{$\begin{array}{l}\text { Item 6: Writing finding section for the } \\
\text { research report }\end{array}$} & Before & 1.06 & 0.24 & \multirow{2}{*}{$-.759(-0.856,-0.663)$} & \multirow{2}{*}{78} & \multirow{2}{*}{$<0.001$} \\
\hline & After & 1.82 & 0.38 & & & \\
\hline \multirow{2}{*}{$\begin{array}{l}\text { Item } 7 \text { : Writing discussion section for the } \\
\text { research report }\end{array}$} & Before & 1.06 & 0.24 & \multirow{2}{*}{$-.759(-0.856,-0.663)$} & \multirow{2}{*}{78} & \multirow{2}{*}{$<0.001$} \\
\hline & After & 1.82 & 0.38 & & & \\
\hline \multirow{2}{*}{$\begin{array}{l}\text { Item 8: Writing conclusion section for the } \\
\text { research report }\end{array}$} & Before & 1.09 & 0.28 & \multirow{2}{*}{$-.696(-0.800,-0.592)$} & \multirow{2}{*}{78} & \multirow{2}{*}{$<0.001$} \\
\hline & After & 1.78 & 0.41 & & & \\
\hline \multirow{2}{*}{$\begin{array}{l}\text { Item 9: Writing references for the } \\
\text { research report }\end{array}$} & Before & 1.11 & 0.32 & $-607(-0.718,-0.497)$ & 78 & $<0.001$ \\
\hline & After & 1.72 & 0.45 & $-.007(-0.110,-0.491)$ & 10 & -0.001 \\
\hline Item 10: Overall knowledge on research & Before & 1.06 & 0.24 & & & $<00001$ \\
\hline process & After & 1.87 & 0.33 & $-.810(-0.900,-0.122)$ & 18 & $<0.001$ \\
\hline
\end{tabular}

$\mathrm{SD}=$ standard deviation

The findings showed that more than $50 \%$ of the students had rated that their knowledge on all the research components had increased after completing the course. Table 2 summarized the students' knowledge on research before and after attending the course. Paired T-test was calculated and there were significant changes observed in the student's knowledge of research components before and after completing the course $(\mathrm{p}<.05)$. (Table 2)

\section{Discussion}

The elective research course was designed in such a manner where the students have to attend a few didactic sessions and then get the experience of conducting their own research project with guidance from their respective supervisor. In this present study, with the opportunity to get first-hand experience of doing 
research, the students have rated that their knowledge of research process has changed after following the one year course.

This finding is supported by a study conducted by DeHaven and Chen (2012) where their students' understanding of general research principles improved after attending 12 didactic sessions and completed a participatory project [8]. Another study, Jamali et al. (2012) stated that attendance for research methodology workshop was one of the important factors that may strengthen students' knowledge on research process [9]. Apart from that, a good supervisory practice also played an important role in bridging the theoretical and practical parts of research process [10].

Millar et al. (2009) suggested that the research course is best integrated with the real-world research. By doing so the students are able to practise what they have learnt in class to the real environment. Thus, the students will indirectly develop positive attitude and inculcate the research culture in their future career [11].

\section{Conclusion}

The elective course appears to increase students' knowledge of research processes. By acquiring knowledge in research processes, hopefully these future doctors can inculcate research in their medical practice.

\section{Reference}

1. Burgoyne LN, O’Flynn S, Boylan GB. Undergraduate medical research: the student perspective. Medical Education Online. 2010;15:5212:1-10.

2. Madan CR, Teitge BD. The benefits of undergraduate research: The student's perspective. The Mentor. 2013:1-3.

3. Murdoch-Eaton D, Drewery S, Elton S, ,Emmerson C, Smith MM. Ja Stark P, Whittle S. What do medical students understand by research and research skills? Identifying research opportunities within undergraduate projects. Medical Teacher. 2010;32:152-160.
4. Houlden LR, Raja BJ, Collier PC, Clark FA, Waugh MJ. Medical students' perceptions of an undergraduate research elective. Medical teacher. 2004:26:7:659-661.

5. Parsonnet J, Gruppuso AP, Kanter LS, Boninger $M$. Required vs elective research and in-depth scholarship programs in the medical student curriculum. Academic Medicine. 2010:85:3:405-408.

6. Amin $\mathrm{T}$, Kaliyadan F, Al Qattan E, Al Majed M, Al Khanjaf H, Mirza M. Knowledge, attitudes and barriers related to participation of medical students in research in three Arab Universities, Education in Medicine Journal. 2012;4:1:43-56.

7. Peacock GJ, Warner LL, Drozdowicz BL, Martin AB, Suresh R, Denzer J, Bonnie. WBA, Adefusika AJ, Bachman JM, Grande PJ. Curricular flexibility in the pre-clinical years promotes medical student scholarship, The Journal of the International Association of Medical Science Educators. 2013:23:1: 92-98.

8. DeHaven MJ. Chen L. Teaching medical students' research while reaching the underserved. Innovations in Family Medicine Education. 2005; 37:5:315-317.

9. Jamali A. Aghdam FA. Hassanpour K. Moghaddam KM. Undergraduate medical students' knowledge about principle of research methodology and impact of extracurricular principles of research workshops: A Cross-sectional study in Tehran University of Medical Sciences. 2012; 1:1:8-12.

10. MacDougall M, Riley SC. Initiating undergraduate medical students into communities of research practise: what do supervisors recommend? BMC Medical Education. 2010; 10:83:1-11.

11. Millar E, Baker MG, Howden-Chapman P, Wilson N, Dickson N. Involving students in real-world research: A pilot study for teaching public health and research skills. BMC medical education. 2009; 9:45: 1-7. 